\title{
Probabilistic Drought Forecasting in Southern Taiwan Using EI Niño-Southern Oscillation Index
}

\author{
Shien-Tsung Chen ${ }^{1}$, Tao-Chang Yang ${ }^{2}$, Chen-Min Kuo ${ }^{2}$, Chih-Hao Kuo ${ }^{2}$, and Pao-Shan $\mathrm{Yu}^{2, *}$ \\ 1 Department of Water Resources Engineering and Conservation, Feng Chia University, Taichung, Taiwan \\ 2 Department of Hydraulic and Ocean Engineering, National Cheng Kung University, Tainan, Taiwan
}

Received 22 February 2013, accepted 4 June 2013

\begin{abstract}
This study proposes a probabilistic drought forecasting model to forecast meteorological drought in Southern Taiwan using the El Niño-Southern Oscillation (ENSO) index. Meteorological drought is defined by the standardized precipitation index (SPI), and the ENSO index is El Niño sea surface temperature (SST). Two probabilistic forecasting model architectures were constructed based on the transition probabilities from El Niño SSTs to SPIs. Both model architectures forecast a one-month-ahead probability distribution for meteorological drought using different combinations of El Niño SST variables. Forecasting results showed the robustness of the probabilistic drought forecasting models. In addition, this study discussed the selection of El Niño SST variables used in the probabilistic drought forecasting model, and found that models with a single SST input outperformed those with multiple SST inputs.
\end{abstract}

Key words: Drought, Probabilistic forecasting, ENSO, Transition probability, El Niño sea surface temperature

Citation: Chen, S. T., T. C. Yang, C. M. Kuo, C. H. Kuo, and P. S. Yu, 2013: Probabilistic drought forecasting in Southern Taiwan using El Niño-Southern Oscillation index. Terr. Atmos. Ocean. Sci., 24, 911-924, doi: 10.3319/TAO.2013.06.04.01(Hy)

\section{INTRODUCTION}

A drought can be classified as meteorological, agricultural, or hydrological, based on the hydrological components considered. Although there are differing classifications of droughts, all types of droughts originate from a shortage of precipitation. The interannual precipitation variability in Taiwan is large, and the precipitations in the dry and wet seasons within a given year are quite distinct. Therefore, Taiwan frequently faces the threat of drought, making drought monitoring and forecasting an important issue.

This study examines the type of meteorological drought that features an extended period of below normal levels of precipitation. Meteorological droughts are expressed in terms of the standardized precipitation index (SPI) proposed by McKee et al. (1993). The SPI is easy to apply, and has various advantages, as discussed by Hayes et al. (1999). Therefore, the SPI has been widely used to investigate meteorological droughts in many countries, including Australia (Wen et al. 2011), Canada (Quiring and Papakryiakou 2003), China (Wu et al. 2001; Liu et al. 2012),

\footnotetext{
* Corresponding author

E-mail:yups@ncku.edu.tw
}

Greece (Tsakiris and Vangelis 2004; Dimitrakopoulos et al. 2011), India (Mishra and Desai 2005), Italy (Bonaccorso et al. 2003; Piccarreta et al. 2004), Spain (Lana et al. 2001; Pasho et al. 2011), Taiwan (Shiau 2006; Chen et al. 2009), and the United States (Edwards and McKee 1997; Ji and Peters 2003).

Drought is dominated by regional precipitation patterns that are influenced by large-scale atmospheric circulation. Taiwan is located in the northwestern part of the Pacific Ocean; therefore, rainfall and drought in Taiwan are heavily influenced by Pacific ocean-atmosphere systems. The El Niño-Southern Oscillation (ENSO) is a large-scale climate and ocean phenomenon across the tropical Pacific Ocean. Therefore, ENSO has been reported to affect the climate and weather in Taiwan, as well as many other places worldwide (e.g., Chen and Lu 2000; Li and Wang 2005; Deng et al. 2008; Zhang and Li 2008; Chen et al. 2012). ENSO is conventionally identified as the warming of the sea surface temperature (SST) in the eastern Pacific (EP), i.e., the EP ENSO. Recently, another type of ENSO has also been reported in the central Pacific (CP) that is referred to as the $\mathrm{CP}$ ENSO (e.g., Hendon et al. 2009; Kao and Yu 2009; Yu and 
Kim 2010; Yu et al. 2012). This study focused on the conventional EP ENSO that is identified using the SST indices.

Many studies have described the teleconnection between droughts and ENSO and its applications. For example, Janicot et al. (1996) analyzed the correlation between Sahel droughts and ENSO and explained how the dynamics of ENSO forcings contributed to the Sahel droughts. Rajagopalan et al. (2000) investigated the spatial structure of teleconnections between the winter ENSO and summer droughts for the continental United States, discussing drought teleconnections in response to ENSO during different decades in the twentieth century. Manatsa et al. (2008) used ENSO-related information (extreme positive sea level pressure anomalies at Darwin, Australia) to predict drought in Zimbabwe. Ryu et al. (2010) investigated the relationship between the multivariate ENSO index and hydrologic drought in the United States, exploring the spatial and temporal variations of hydrologic droughts corresponding to ENSO events. VicenteSerrano et al. (2011) analyzed the influence of the ENSO phenomenon on drought severity at the global scale to reveal the differing impacts of ENSO on severity, timescales, and periods of drought. Hallack-Alegria et al. (2012) confirmed the correlation of seasonal and annual precipitation in Northwest Baja California, Mexico, with ENSO, and analyzed drought frequency conditional to the ENSO indices.

Research on the ENSO effects on the climate and weather in Taiwan usually focuses on the spring rainfall. $\mathrm{Lu}$ (2002) identified the biennial oscillation signal of January and February precipitation in Taiwan, finding that the biennial oscillation of precipitation is associated with the biennial oscillation signal of ENSO, revealing that the local climate in Taiwan is influenced by low-frequency variations of tropical and extratropical climate systems. Jiang et al. (2003) examined the effect of interdecadal variation on the relationship between spring rainfall (February and March) and ENSO, elucidating the characteristics of large-scale circulations associated with heavy spring rainfall events in Taiwan in strong ENSO and non-ENSO years. Chen et al. (2008) studied the asymmetric relationship between spring rainfall (February, March, and April) in Taiwan and ENSO. This asymmetric relationship shows that spring rainfall in Taiwan can be enhanced or suppressed by an El Niño event because of connections between ENSO and the Indian Ocean SST anomaly and associated large-scale atmospheric circulation. Kuo et al. (2010) used wavelet analysis to analyze the variability and oscillations from November to January and January to March rainfall levels in Taiwan and the seasonal SST of the Pacific Ocean.

Research on the connection between rainfall in seasons other than spring in Taiwan and ENSO is scant. This is because rainfall in the summer and autumn in Taiwan is dominated by typhoons, which are weakly connected to ENSO. Because the spring rainfall in Taiwan can be either enhanced or suppressed by an El Niño event, and the summer and autumn rainfall in Taiwan has little direct correlation with ENSO, the obtainment of drought information in Taiwan from ENSO is difficult. Therefore, we used a probabilistic model based on our previous study (Kuo et al. 2012) to forecast meteorological drought in Taiwan from ENSO SSTs. The probabilistic model in this study is based on the concept of transition probability. Two forecasting model architectures were constructed in accordance with the two types of transition probability matrices of drought state and SST state in different time horizons. The first transition probability matrix was built pertaining to drought state and SST state in the same month; the other was constructed using the drought state in the present month and SST state in the previous month.

The methodology of the transition probability matrix and the probabilistic model architecture is described in section 2 (Methodology). The data description used in this study is provided in section 3 (Study Area and Data Sets). The analytical process and results, including the probabilistic model development, probabilistic drought forecasting results, and a comparison of the forecasting performance of the two model architectures, are presented in Section 4 (Results and Discussion). In addition, this study examined various combinations of SST variables and discusses the selection of the ENSO SST variables used in the probabilistic drought forecasting model. Section 5 (Conclusions) offers concluding remarks.

\section{METHODOLOGY}

\subsection{Drought Definition}

The SPI, proposed by McKee et al. (1993), was used to define the meteorological drought in this study. The first step in the SPI calculation was to fit the precipitation data to a probability distribution. Thereafter, the cumulative probability of precipitation could be derived from the probability distribution function. This cumulative probability was converted into a standard normal variable with a mean value of zero and a variance value of one (i.e., the SPI took on the value of a standard normal variable). Therefore, negative SPI values imply that precipitation is less than the median. Consequently, positive and negative SPI values indicate wet and dry conditions, respectively. Different levels of drought can be defined according to the differing thresholds of negative SPI values. Detailed description of the SPI calculation can be found in the Lloyd-Hughes and Saunders (2002) study.

\subsection{ENSO Indices}

ENSO can have effects on regional rainfall worldwide. Therefore, scientists developed a number of indices to monitor ENSO events. Two groups of ENSO indices are 
commonly used. One group of indices is based on the surface atmospheric pressure, and the other is based on the SST. A well-known index of the former group is the Southern Oscillation Index (SOI), which is the pressure difference between the eastern and western tropical Pacific (i.e., Tahiti and Darwin, respectively). The latter group often refers to the SST of specific regions along the equatorial Pacific, in which SST regions of El Niño $1+2\left(0^{\circ}-10^{\circ} \mathrm{S}, 90^{\circ}-80^{\circ} \mathrm{W}\right)$, El Niño $3\left(5^{\circ} \mathrm{N}-5^{\circ} \mathrm{S}, 150^{\circ}-90^{\circ} \mathrm{W}\right)$, El Niño $3.4\left(5^{\circ} \mathrm{N}-5^{\circ} \mathrm{S}\right.$, $\left.170^{\circ}-120^{\circ} \mathrm{W}\right)$, and El Niño $4\left(5^{\circ} \mathrm{N}-5^{\circ} \mathrm{S}, 160^{\circ} \mathrm{E}-150^{\circ} \mathrm{W}\right)$ are well known. El Niño SST is a more direct measure of ENSO relative to the SOI. Therefore, this study used El Niño SST as the ENSO index in the analysis.

\subsection{Transition Probability Construction}

This study employed a concept similar to a Markov chain to build a probabilistic model that used the El Niño SST state as the input to determine the probabilities of different states of the SPI. A Markov chain is a process in which the state of a variable at the present time step changes depending on the states of the same variable at previous time steps. The changes of state are the transitions, and the probabilities pertaining to the changes among states are called transition probabilities. Two essential elements of the Markov chain are the definition of states and the derivation of the transition probability matrix among states. The study also used the terminology of a Markov chain to elucidate the proposed probabilistic model, although the proposed model is not a Markov chain model.

The probabilistic model establishes the state transition probability matrix between El Niño SST and SPI variables. The first step is to split the variables into several states. Based on the data properties and the preliminary test work, the monthly El Niño SST was divided into $u$ states with an interval increment of $0.2^{\circ} \mathrm{C}$, and the monthly SPI was divided into $v$ states with an interval increment of one. Thereafter, the numbers of state transitions $n_{i j}$ were calculated with respect to the observed data, where $i$ was the state of El Niño $\operatorname{SST}(i=1,2, \ldots, u) ; j$ was the state of SPI $(j=1,2, \ldots, v)$; and $n_{i j}$ indicated the El Niño SST state $i$ that corresponded to the SPI state $j$. Therefore, the matrix of transition numbers can be written as Eq. (1).

$\left[\begin{array}{cccc}n_{11} & n_{12} & \cdots & n_{1 v} \\ n_{21} & n_{22} & \cdots & n_{2 v} \\ \vdots & \vdots & \ddots & \vdots \\ n_{u 1} & n_{u 2} & \cdots & n_{u v}\end{array}\right]$

Next, let $n_{i j}$ be divided by $N_{i}$, where $N_{i}$ is the total number of El Niño SST values that falls within state $i$, as shown by the following equation:
$N_{i}=n_{i 1}+n_{i 2}+\cdots+n_{i v}$

The transition probability $p_{i j}$ can thus be calculated by

$p_{i j}=n_{i j} / N_{i}$

Consequently, the transition probability matrix $P$ from $\mathrm{El}$ Niño SST to SPI variables was derived as Eq. (4).

$P=\left[\begin{array}{cccc}p_{11} & p_{12} & \cdots & p_{1 v} \\ p_{21} & p_{22} & \cdots & p_{2 v} \\ \vdots & \vdots & \ddots & \vdots \\ p_{u 1} & p_{u 2} & \cdots & p_{u v}\end{array}\right]$

With the transition probability matrix $P$, the probability of occurrence of SPI state $j$, conditional on El Niño SST state $i$ can be specified as $p_{i j}$. The summation of all $p_{i j}$ in a certain row $i$ is one. Furthermore, where no historical El Niño SST data exist in a certain ith state, the transition probabilities in the $i$ th row are all zero. The state transition probability matrix $P$ built by El Niño SST and SPI variables at the same time $t$ can be represented as a conditional probability form in Eq. (5).

$P[$ state $j$ of $S P I(t) \mid$ state $i$ of $S S T(t)]$

Figure 1 shows an example of transition probability construction. Monthly El Niño SST data were divided into several states with an interval increment of $0.2^{\circ} \mathrm{C}$, and SPI with an interval increment of one. Whereas the SST data were within the state of the interval, for example, $\left[24.6^{\circ} \mathrm{C}\right.$, $24.8^{\circ} \mathrm{C}$ ), their corresponding SPI during the same month were within states of intervals $(-\infty,-2),[-2,-1),[-1,0),[0$, $1),[1,2)$, and $[2, \infty)$, which had counts of $0,0,1,3,2$, and 1 , respectively. Therefore, the transition probabilities of the respective SPI states conditional on the SST being in the state $\left[24.6^{\circ} \mathrm{C}, 24.8^{\circ} \mathrm{C}\right.$ ) were $0,0,1 / 7,3 / 7,2 / 7$, and $1 / 7$ (i.e., $0,0,0.14,0.43,0.29$, and 0.14$)$. The derived transition probabilities then formed the SPI probability distribution conditional on the SST (as shown in the lower panel of Fig. 1).

\subsection{Probabilistic Drought Forecasting Model}

A state transition probability matrix was used to build the probabilistic drought forecasting model. This study proposes two forecasting model architectures, with the input of El Niño SSTs, to forecast SPI one month ahead. The first model architecture used the state transition probability matrix $P$ built by El Niño SST and SPI variables at the same month $t$, as shown in Eq. (5). To obtain a one-month-ahead forecast 


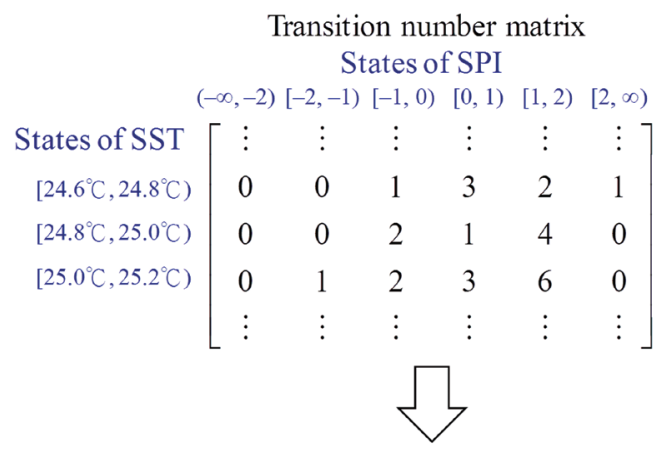

Transition probability matrix States of SPI $(-\infty,-2) \quad[-2,-1) \quad[-1,0) \quad[0,1) \quad[1,2) \quad[2, \infty)$

$(-\infty,-2)$
States of SST
$\left[24.6^{\circ} \mathrm{C}, 24.8^{\circ} \mathrm{C}\right)$
$\left[24.8^{\circ} \mathrm{C}, 25.0^{\circ} \mathrm{C}\right)$
$\left[25.0^{\circ} \mathrm{C}, 25.2^{\circ} \mathrm{C}\right)$$\left[\begin{array}{cccccc}\vdots & \vdots & \vdots & \vdots & \vdots & \vdots \\ \hline 0 & 0 & 0.14 & 0.43 & 0.29 & 0.14 \\ 0 & 0 & 0.29 & 0.14 & 0.57 & 0 \\ 0 & 0.08 & 0.17 & 0.25 & 0.50 & 0 \\ \vdots & \vdots & \vdots & \vdots & \vdots & \vdots\end{array}\right]$

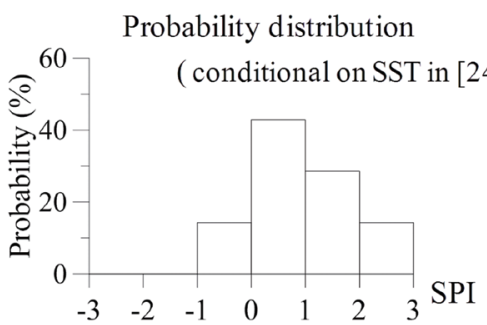

Fig. 1. Example of transition probability and probability distribution construction.

of $\operatorname{SPI}(t+1)$ at the present time $t$, the future $\operatorname{SST}(t+1)$ is needed. This study applied an autoregression model of SST to obtain $\operatorname{SST}(t+1)$ at the next time step. The architecture of the first probabilistic drought forecasting model (Model 1) is shown in Fig. 2. The second model used a state transition probability matrix $P$ built by El Niño SST at time $t$ and SPI at time $t+1$, as shown in Eq. (6).

$P[$ state $j$ of $\operatorname{SPI}(t+1) \mid$ state $i$ of $\operatorname{SST}(t)]$

Using this state transition probability matrix, $\operatorname{SPI}(t+1)$ at the next time step was directly derived using $\operatorname{SST}(t)$ at present. The architecture of the second probabilistic drought forecasting model (Model 2) is shown in Fig. 3.

\section{STUDY AREA AND DATA SETS}

Taiwan is an island located between the northwestern Pacific Ocean and the southeastern coast of the Asian continent. The climate in Taiwan is marine tropical, and the average annual precipitation is approximately $2510 \mathrm{~mm}$, with a rainy season from May to October and a dry season from
November to April. Although the mean precipitation in Taiwan is plentiful, the temporal distribution of the precipitation is uneven. A large proportion of the annual precipitation is delivered by typhoons that last for only a few days. In years where Taiwan experiences few typhoons, belowaverage amounts of precipitation are stored in reservoirs, and drought is probable in the spring of the following year. This type of situation is particularly serious in Southern Taiwan (Fig. 4), where $90 \%$ of the annual rainfall occurs during the wet season. In 2002, a serious drought occurred and had a significant impact on industry and agriculture throughout Taiwan. Huang and Yuan (2004) and Huang and Chou (2008) discussed the 2002 drought from the perspective of reservoir operation.

This study collected long-term monthly precipitation records in Southern Taiwan. Data quality control was conducted to remove suspicious and incomplete data. Consequently, only seven stations (Fig. 4) had completely consecutive and high-quality records from 1950 to 2009. The average monthly precipitation in Southern Taiwan was calculated pertaining to the seven stations by using the arithmetic mean method. The average monthly precipitation distribution in Southern Taiwan during 1950 to 2009 is shown in Fig. 4, and the average annual precipitation in this period was $2039 \mathrm{~mm}$.

The average monthly precipitation series were used to calculate the drought index (i.e., the SPI). This study used precipitation data with a three-month timescale to calculate the SPI series, which satisfactorily reveals meteorological drought in Taiwan (Chen et al. 2009). Therefore, the monthly precipitation at month $t$ was taken as the mean of precipitation data at months $t-2, t-1$, and $t$. Data from the derived three-month precipitation series were then fitted to a probability distribution to calculate the SPI. McKee et al. (1993) used the gamma distribution to fit the monthly precipitation. This study confirmed that the gamma distribution fit the precipitation data at a level of significance of 0.05 by applying the Kolmogorov-Smirnov test to the three-month precipitation data. The gamma distribution was therefore used to transfer the cumulative probability of the threemonth precipitation series into the monthly SPI series.

El Niño SST data used in this study were obtained from the Extended Reconstructed Sea Surface Temperature (ERSST, Version 3b) reconstructed by Smith and Reynolds $(2003,2004)$ and Smith et al. (2008). The ERSST data included regions of El Niño 1 + 2, El Niño 3, El Niño 3.4, and El Niño 4. The monthly ERSST data (1950 to the present) are available at the National Oceanic and Atmospheric Administration (NOAA) Web site (http://www.cpc.ncep.noaa. gov/data/indices).

Consequently, the monthly data of SPI in Southern Taiwan and El Niño SST (four sets of El Niño $1+2$, El Niño 3, El Niño 3.4, and El Niño 4) from 1950 to 2009 were available for this study. Data from 1950 to 2000 (85\% of the 


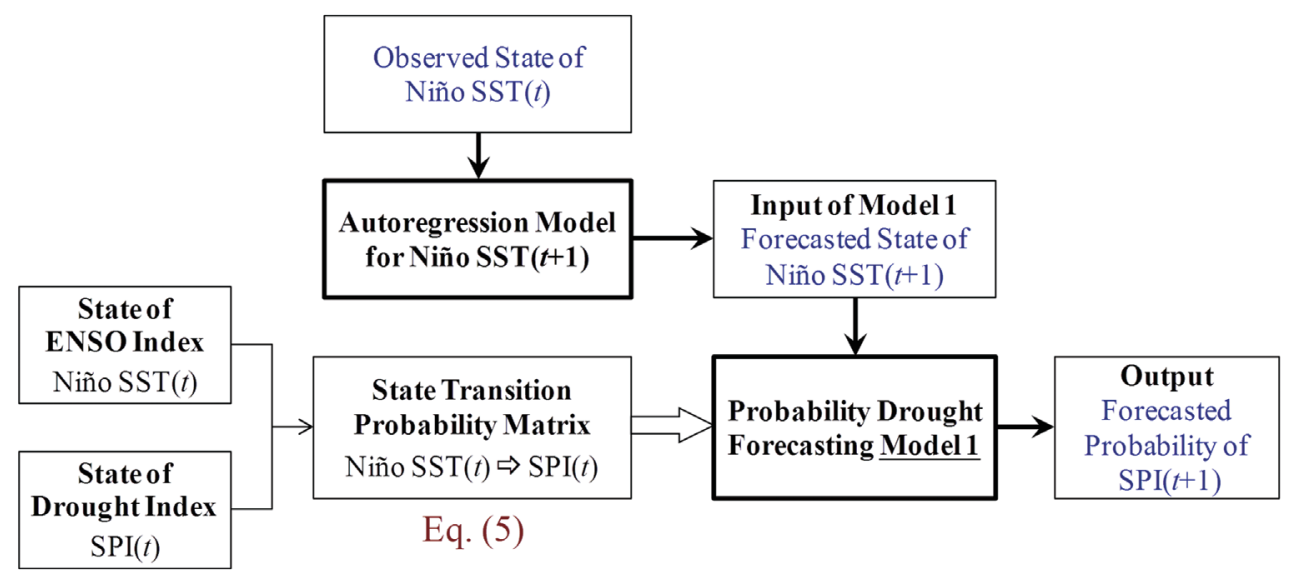

Fig. 2. Architecture of the first probabilistic drought forecasting model (Model 1).

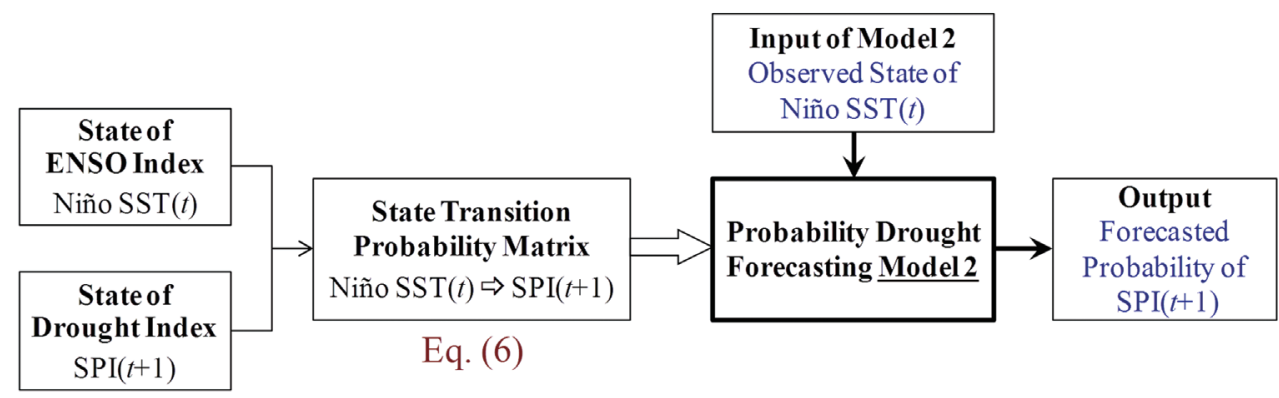

Fig. 3. Architecture of the second probabilistic drought forecasting model (Model 2).

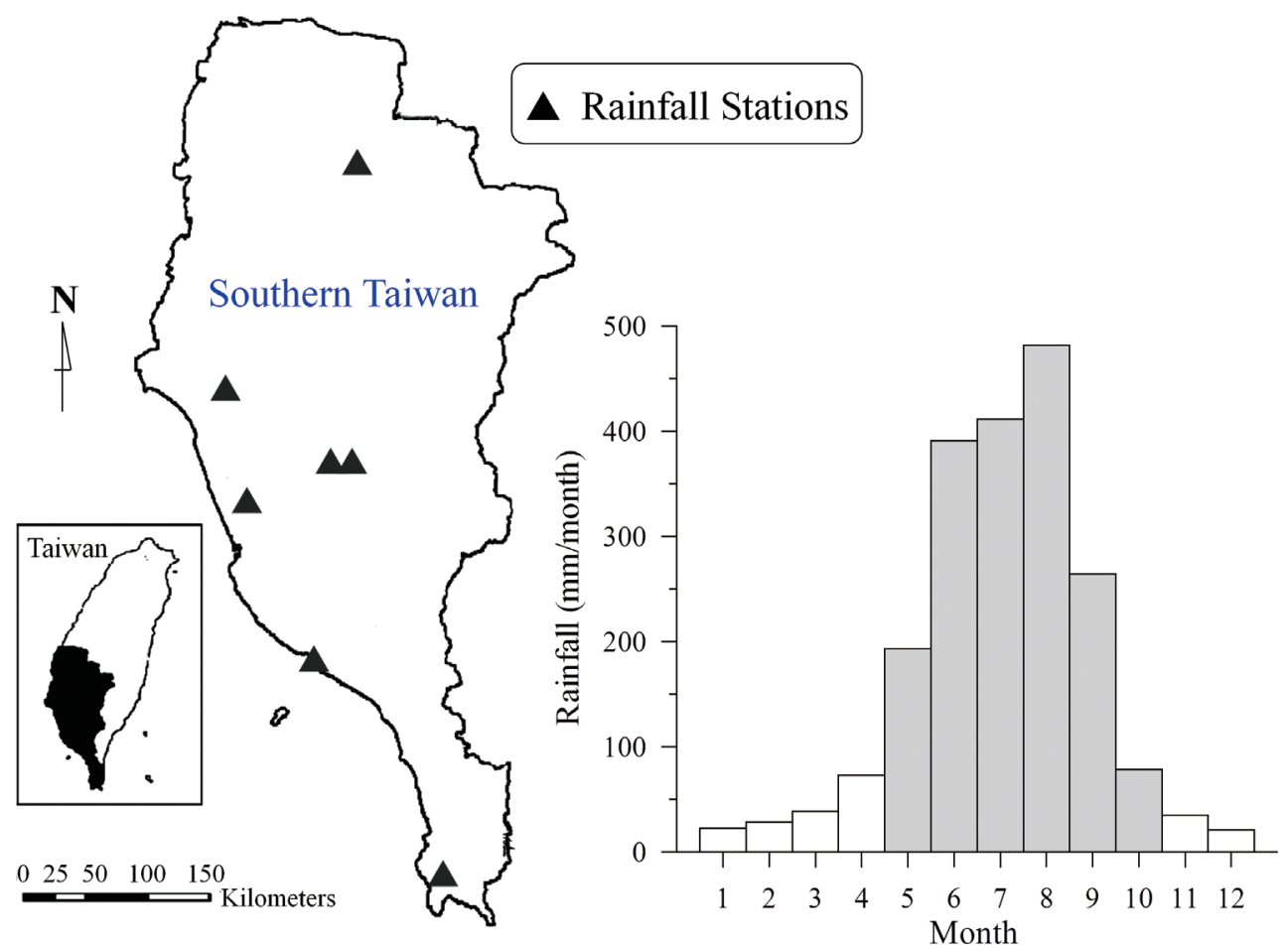

Fig. 4. Study area and monthly precipitation. 
total data) were used for model calibration. The remaining $15 \%$ of the data (from 2001 to 2009) were used for model validation.

\section{RESULTS AND DISCUSSION}

\subsection{Autoregression Model of SST}

To use Model 1 to forecast $\operatorname{SPI}(t+1)$ one month ahead, autoregression models of SST were constructed. The SST data at time $t$ and time $t+1$ pertaining to the calibration period are shown in Fig. 5, exhibiting high autocorrelation between SST data at time $t$ and time $t+1$. Linear regression models can represent the SST relationship. However, exponential regression models better fit the SST data. The autoregression models of four El Niño SST data sets are shown in Eqs. (7) to (10).
El Niño $1+2: \operatorname{SST}(t+1)=9.636 \cdot \exp [0.0376 \cdot \operatorname{SST}(t)]$

El Niño 3: $\operatorname{SST}(t+1)=10.653 \cdot \exp [0.0342 \cdot \operatorname{SST}(t)]$

El Niño 3.4: $\operatorname{SST}(t+1)=10.867 \cdot \exp [0.0337 \cdot \operatorname{SST}(t)]$

El Niño 4: $\operatorname{SST}(t+1)=11.316 \cdot \exp [0.0324 \cdot \operatorname{SST}(t)]$

Table 1 lists the coefficient of correlation (CC) and root mean squared error (RMSE) pertaining to the calibration and validation results of the autoregression models. As shown in Fig. 5 and Table 1, the temperature ranges and accuracies of the autoregression models varied, and had the following characteristics. The El Niño $1+2$ region enclosed a smaller area than did the other El Niño SST regions. Therefore, the
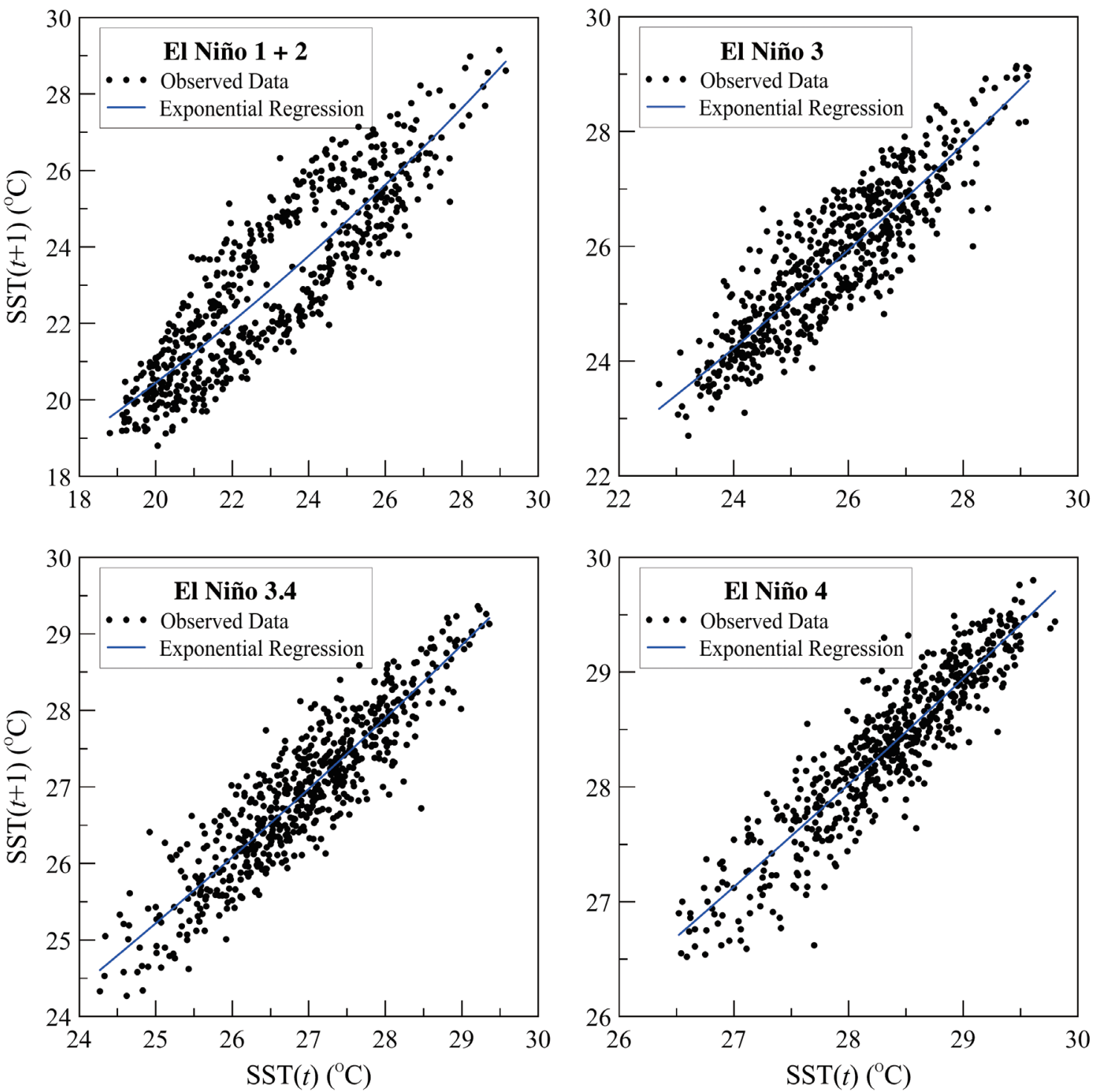

Fig. 5. Relationship of sea surface temperature data at time $t$ and time $t+1$, and their exponential regression lines. 
Table 1. Calibration and validation results of autoregression models of El Niño SSTs.

\begin{tabular}{lcccc}
\hline & \multicolumn{2}{c}{$\mathbf{C C}$} & \multicolumn{2}{c}{ RMSE $\left({ }^{\circ} \mathbf{C}\right)$} \\
\cline { 2 - 5 } & Calibration & Validation & Calibration & Validation \\
\hline El Niño 1+2 & 0.87 & 0.85 & 1.14 & 1.23 \\
El Niño 3 & 0.88 & 0.85 & 0.61 & 0.54 \\
El Niño 3.4 & 0.91 & 0.89 & 0.42 & 0.38 \\
El Niño 4 & 0.91 & 0.93 & 0.28 & 0.27 \\
\hline
\end{tabular}

average temperature in the El Niño $1+2$ region had a larger interval (approximately 18 to $30^{\circ} \mathrm{C}$ ). The additional El Niño SST regions had larger areas and extended toward the west to the central equatorial Pacific. The average temperature changes in these regions were therefore smaller, although they had upper limits (approximately $30^{\circ} \mathrm{C}$ ) that were similar to El Niño $1+2$, and lower limits of approximately 22 , 24, and $26^{\circ} \mathrm{C}$ for El Niño 3, El Niño 3.4, and El Niño 4 SSTs, respectively. Furthermore, the regression models for El Niño $1+2$, El Niño 3, El Niño 3.4, and El Niño 4 in the series had increasing accuracy (with larger CCs and smaller RMSEs), as shown in Table 1.

\subsection{Probabilistic Model Ensemble}

Because four sets of El Niño SST data were available, different combinations of state transitions (from various $\mathrm{El}$ Niño SST combinations to SPI) could be identified. With only one El Niño SST variable as the model input, four state transition probability matrices were built. Therefore, four probabilistic models were developed. Using two El Niño SSTs as the model inputs, six probabilistic models (six combinations of input variables) were derived. In total, 15 probabilistic models $\left(C_{1}^{4}+C_{2}^{4}+C_{3}^{4}+C_{4}^{4}=15\right.$, where $C_{r}^{k}$ indicates the number of combinations to choose $r$ out of $k$ elements) were established. These 15 combinations of El Niño SSTs are shown in the four left columns of Table 2. Each probabilistic model could output a probability distribution of SPI conditional on the inputted El Niño SST states. For conciseness, this study used a multi-model ensemble scheme to combine these 15 probability distributions into one probability distribution. Uniform weights were given to the original 15 probability distributions in the multi-model ensemble procedure.

\subsection{Drought Forecasting}

Various combinations of El Niño SSTs as input variables were used to construct 15 transition probability matrices.

Table 2. Comparison of model scores.

\begin{tabular}{|c|c|c|c|c|c|c|c|}
\hline \multicolumn{4}{|c|}{ Combination of inputs (EI Niño SSTs) } & \multicolumn{2}{|c|}{ Model 1} & \multicolumn{2}{|c|}{ Model 2} \\
\hline El Niño 1 + 2 & El Niño 3 & El Niño 3.4 & El Niño 4 & SPI $<0$ & $\mathrm{SPI}>0$ & $\mathrm{SPI}<0$ & $\mathrm{SPI}>0$ \\
\hline \multirow[t]{4}{*}{$\mathrm{V}$} & & & & 17.38 & 11.91 & 16.46 & 11.07 \\
\hline & $\mathrm{V}$ & & & 17.83 & 12.10 & 17.07 & 12.70 \\
\hline & & $\mathrm{V}$ & & 15.96 & 11.70 & 16.01 & 12.21 \\
\hline & & & $\mathrm{V}$ & 17.00 & 12.36 & 16.40 & 11.61 \\
\hline $\mathrm{V}$ & $\mathrm{V}$ & & & 11.71 & 10.07 & 11.66 & 7.11 \\
\hline $\mathrm{V}$ & & $\mathrm{V}$ & & 13.89 & 9.24 & 6.25 & 5.16 \\
\hline \multirow[t]{4}{*}{$\mathrm{V}$} & & & $\mathrm{V}$ & 9.14 & 9.62 & 7.29 & 4.50 \\
\hline & $\mathrm{V}$ & $\mathrm{V}$ & & 14.62 & 8.11 & 14.91 & 8.66 \\
\hline & V & & $\mathrm{V}$ & 16.07 & 9.92 & 10.11 & 13.85 \\
\hline & & V & V & 18.70 & 8.59 & 12.19 & 9.92 \\
\hline $\mathrm{V}$ & $\mathrm{V}$ & V & & 14.88 & 10.13 & 11.01 & 5.09 \\
\hline $\mathrm{V}$ & $\mathrm{V}$ & & V & 14.38 & 12.95 & 9.60 & 7.23 \\
\hline \multirow[t]{2}{*}{$\mathrm{V}$} & & V & V & 14.62 & 11.88 & 10.87 & 8.91 \\
\hline & V & V & $\mathrm{V}$ & 16.29 & 10.33 & 15.68 & 8.70 \\
\hline \multirow[t]{2}{*}{$\mathrm{V}$} & V & V & V & 8.87 & 9.08 & 7.08 & 3.83 \\
\hline & Multi-m & ensemble & & 14.76 & 10.53 & 12.17 & 8.70 \\
\hline
\end{tabular}


The transition probability matrices in Eq. (5) were calibrated using calibration data. Thereafter, the 15 drought forecasting models (Model 1) were established with the calibrated transition probability matrices and the autoregression models for El Niño SSTs. These drought forecasting models were applied for validation data (monthly data from 2001 to 2009) to forecast one-month-ahead SPI probability distributions conditional on El Niño SST data in the present month.

Each monthly SPI probability distribution was a probabilistic forecast of drought from El Niño SSTs. For example, the model that used El Niño 4 data as the single input variable forecasted the probability distribution of SPI in January 2002, as shown in Fig. 6a. The probabilistic distribution indicated that the observed SPI would probably appear in the interval $[-1,0)$ with the highest probability; the second probable interval in which the observed SPI would appear was $[0,1)$. The observed SPI in January 2002 was -0.74 , as shown in Fig. 6 (denoted with the star sign), indicating that this forecasted probabilistic distribution of SPI was practical. Using the 15 forecasted probability distributions from all models, the ensemble probability distribution was calculated, as shown in Fig. 6b. The result from this multimodel ensemble did not outperform that of the single model (with El Niño 4 as the input variable) in the case of January 2002. The Model 2 results for January 2002, pertaining to the El Niño 4 model and multi-model ensemble, are shown in Figs. $6 \mathrm{c}$ and d, respectively. Both forecasted probability distributions demonstrated robust results because they predicted the highest probability of the interval $[-1,0)$, in which the observed SPI occurred.

The multi-model ensembles of the forecasted SPI probability distributions for 2002 concerning Models 1 and 2 are shown in Figs. 7 and 8, respectively. The negative SPI values in all months throughout the year indicated that 2002 was a drought year. The multi-model ensemble of the forecasted probability distributions can reflect the probabilistic characteristics of the SPI. However, for some months, the results were unsatisfactory. We calculated the number of observed SPIs that was properly positioned within the interval with the highest probability during the validation period. For clarity, the interval with the highest probability was termed Interval 1, similar to the interval $[-1,0)$ shown in Fig. 6a; the interval with the second highest probability was termed Interval 2, similar to the interval $[0,1)$ shown in Fig. 6 a; and so on. The numbers that had the observed SPIs located within Interval 1 to Interval 6 (multi-model ensemble results) were (a)
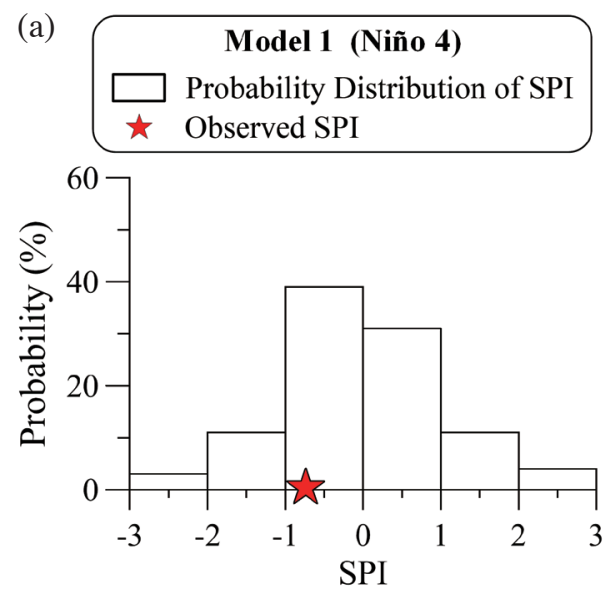

(c)
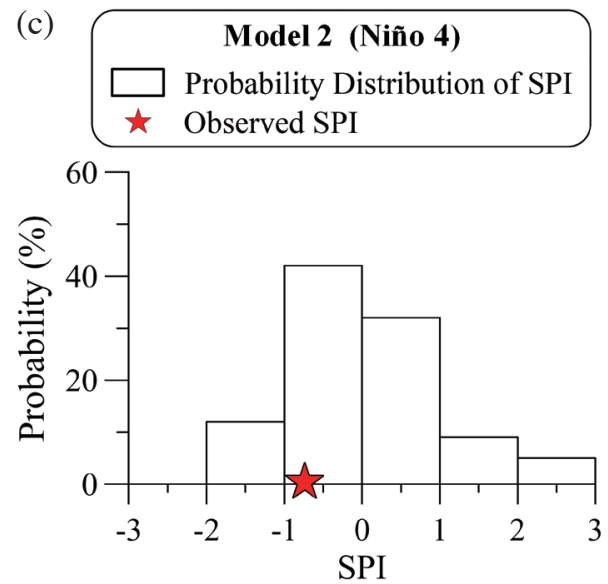

(b)
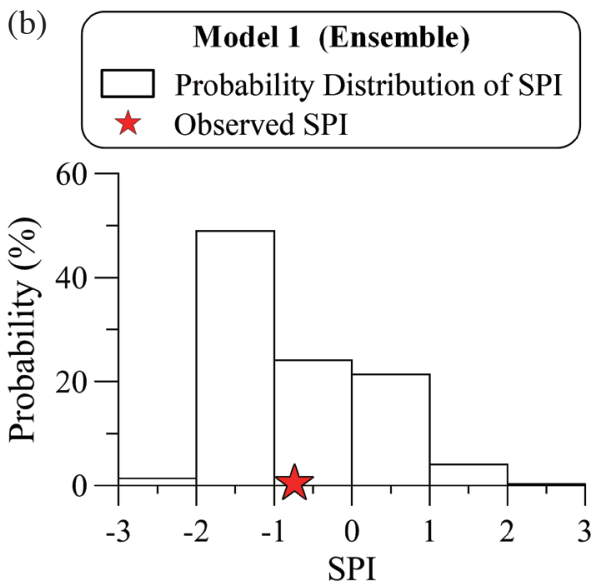

(d)
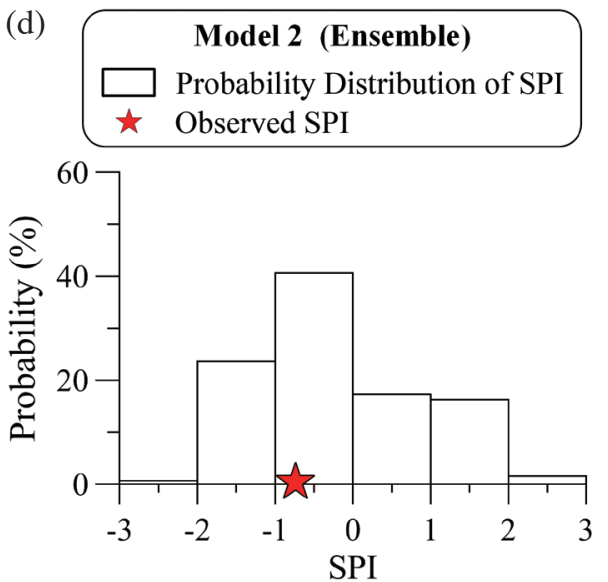

Fig. 6. Forecasted SPI in January 2002. 


\section{Model 1 (2002) $\square$ Forecasted probability of SPI}
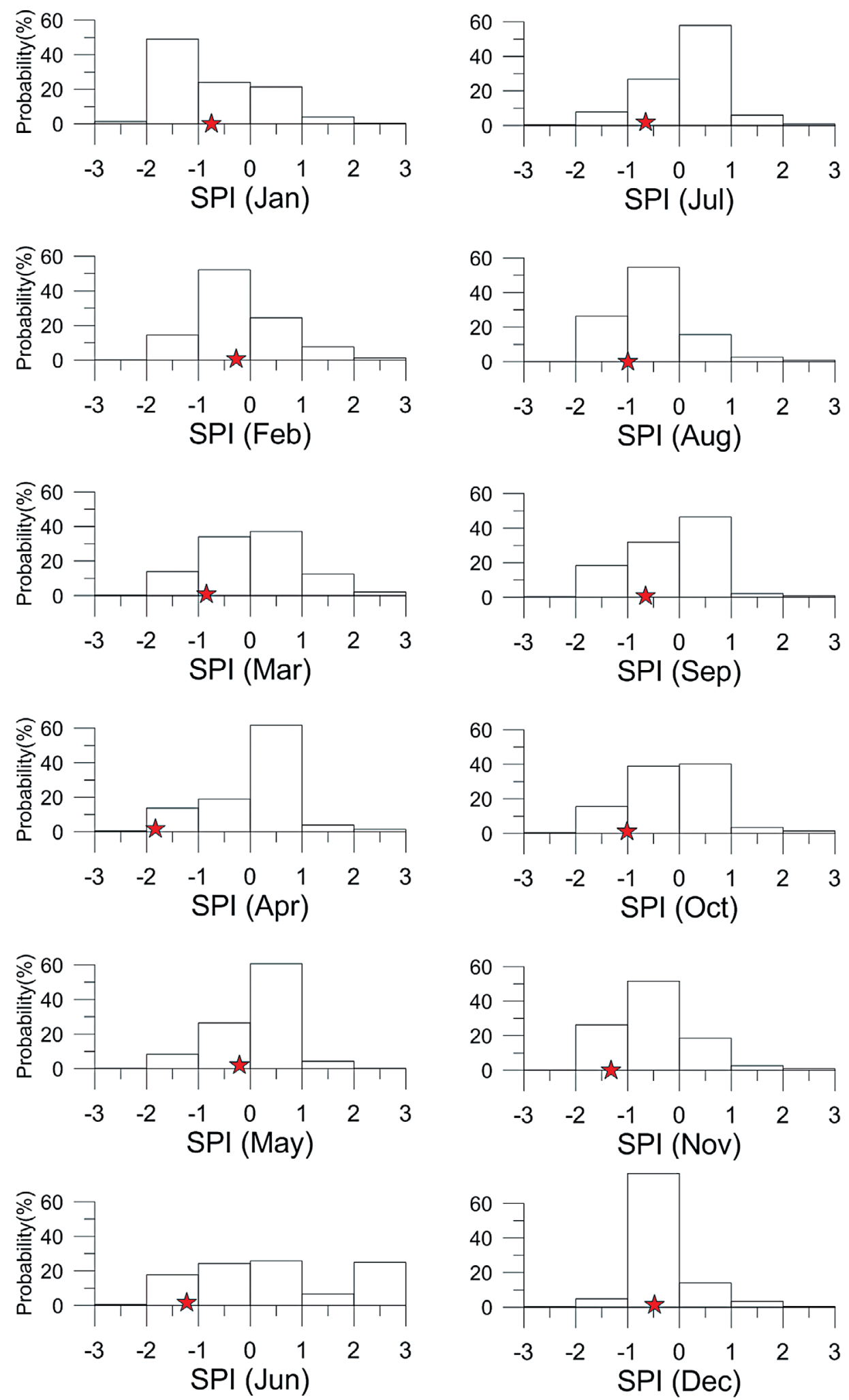

Fig. 7. Multi-model ensemble of SPI probability distribution in 2002 (Model 1). 
\begin{tabular}{l|l|} 
Model 2 (2002) & $\begin{array}{l}\square \text { Forecasted probability of SPI } \\
\star \text { Observed monthly SPI }\end{array}$ \\
\hline
\end{tabular}
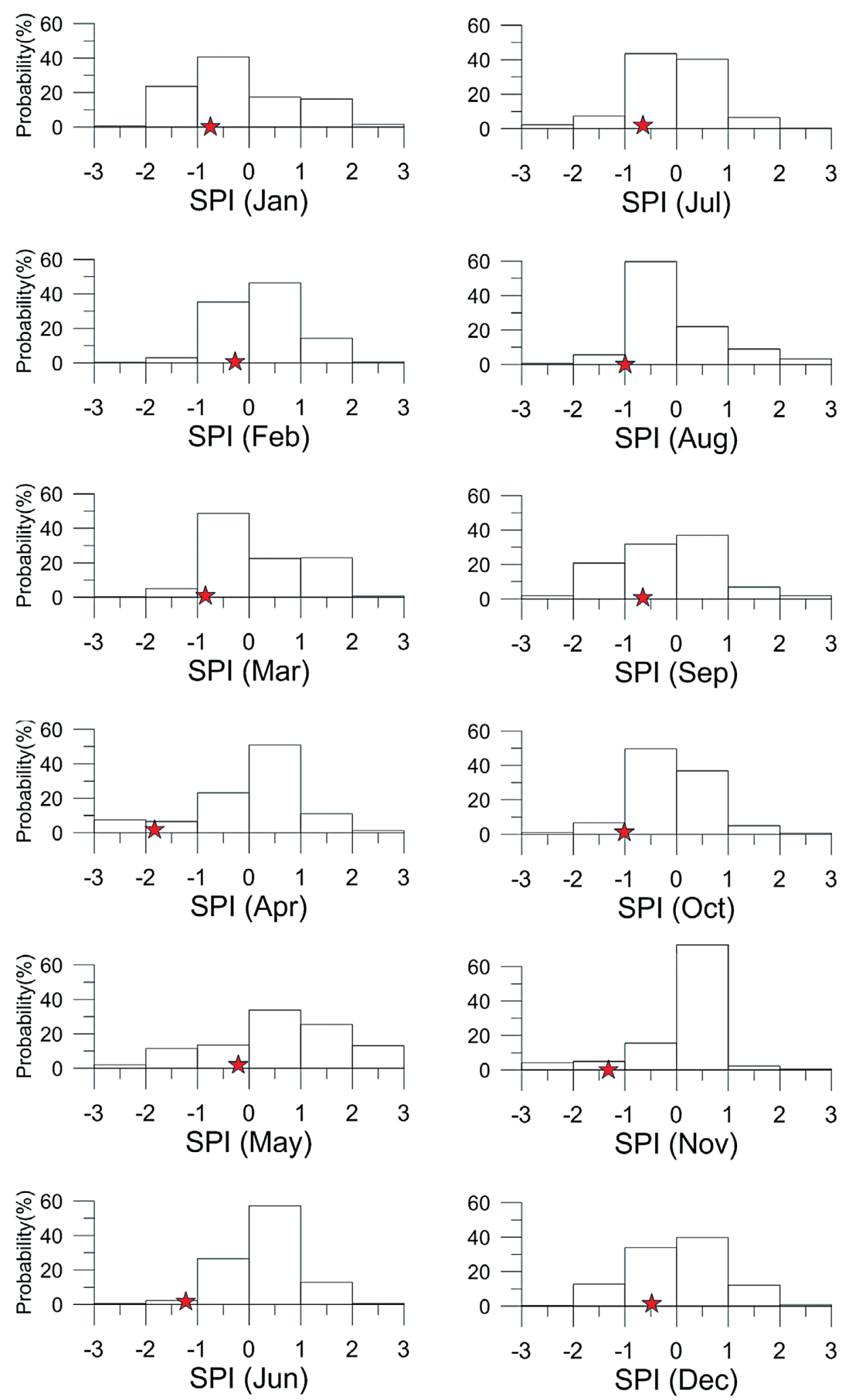

Fig. 8. Multi-model ensemble of SPI probability distribution in 2002 (Model 2). 
respectively $38,24,18,14,4$, and 0 for Model 1 . The numbers that had the observed SPIs within Interval 1 to Interval 6 were correspondingly 30, 36, 21, 15, 3, and 2 for Model 2 . Note that the sum of the numbers within intervals is not equal to the number of monthly SPI values in the calibration set (that is, 108), because when no historical SST data exist in a certain $i$ th state, the transition probabilities in the $i$ th row are all zero. Thus, when the current SST state matches the row with all zero values in the transition probability matrix, the model output shows no probability distribution. The results for numbers that were properly positioned within the intervals demonstrate that the proposed probabilistic forecasting method is practical for drought forecasting. Furthermore, assuming that more observed SPIs within Interval 1 were better for forecasting, Model 1 outperformed Model 2.

\subsection{Comparison of Model Performance and El Niño SSTs}

To assess the probabilistic forecasting performance, this study used a simple score that was the probability value dependent on the observed SST states and the observed SPI interval. Figure 1 can be used to show the proposed model score. For example, when an observed monthly data pair of SST and SPI was $\left(24.7^{\circ} \mathrm{C}, 0.3\right)$, the forecasting model gave a forecasted probability distribution of $0,0,0.14,0.43,0.29$, and 0.14 for each SPI interval conditional on the SST of $24.7^{\circ} \mathrm{C}$. In this condition, the observed SPI value of 0.3 was in the interval of $[0,1)$. The model therefore obtained a high score of 0.43 because it precisely forecasted with a high probability that the SPI would be in the interval of $[0,1)$. Furthermore, when an observed data pair of SST and SPI was $\left(25.1^{\circ} \mathrm{C},-1.2\right)$, the forecasting model forecasted a probability distribution of $0,0.08,0.17,0.25,0.50$, and 0 for each SPI interval under an SST of $25.1^{\circ} \mathrm{C}$. The observed SPI value of -1.2 was within the interval of $[-2,-1)$. Therefore, the model obtained a low score of 0.08 because it gave a low probability of 0.08 for the second interval of $[-2,-1)$. The proposed score followed the probability concept and was easy to compute. The final model score was determined as the sum of all the monthly scores.

Score $=\sum_{t=1}^{T} p_{i j}(t)$

The score in Eq. (11) is dependent on the observed $\operatorname{SST}(t)$ in the $i$ th state, the observed $\operatorname{SPI}(t)$ in the $j$ th state, and the month $t=1,2, \ldots, T$.

Scores that pertained to all 15 models and the ensemble model were calculated during the validation period to review the model's performance. To further show the model's performance pertaining to dry conditions $(\mathrm{SPI}<0)$ and wet conditions (SPI $>0$ ), the model scores in the two cases (dry and wet) are shown in Table 2. The left-hand side of
Table 2 shows the combinations of the SST input variables. The check marks indicate the variables used in the model. The right-hand side of Table 2 shows the scores from the results of all 15 models, as well as the ensemble model for Models 1 and 2. Models with higher scores have better forecasting performances. Considering the dry and wet conditions, the model scores for dry conditions $($ SPI $<0)$ are generally higher than those for wet conditions (SPI $>0$ ), indicating that the proposed probabilistic forecasting model is better suited to predicting drought conditions than to predicting wet conditions.

Model 1 had higher scores and outperformed Model 2. Model 1 used SST forecasts from autoregression models. Although autoregression models include forecasting errors, Model 1 was still more accurate than Model 2. The state transition probability matrix of Eq. (5) used in Model 1 was therefore more efficient than that of Eq. (6), which was used in Model 2. The state transition probability matrix of Eq. (5) was built using El Niño SST and SPI variables in the same month, whereas that of Eq. (6) was constructed using SST in month $t$ and SPI in month $t+1$. These results imply that using El Niño SST in the same month is more informative for drought forecasting in Southern Taiwan than using El Niño SST in the previous month.

Regarding the forecasting performance among models with different El Niño SST variables, a comparison shows that models with single El Niño SST inputs had higher scores. Models with multiple El Niño SST inputs did not have improved forecasting performances. The three worst models were those with inputs as (El Niño $1+2$, El Niño 3.4), (El Niño $1+2$, El Niño 4), and (El Niño $1+2$, El Niño 3, El Niño 3.4, El Niño 4). The regions El Niño $1+2$ and El Niño 3.4 were distant from each other; therefore, the SSTs of these regions had low correlations. The correlation coefficient of El Niño $1+2$ and El Niño 3.4 SSTs during the calibration period was 0.47 . The regions El Niño $1+2$ and El Niño 4 were also far apart. The correlation coefficient of El Niño $1+2$ and El Niño 4 SSTs was only 0.11 . Occasionally, the SST variability in the El Niño $1+2$ and El Niño 3.4 (and El Niño 4) regions did not have the same temperature phase. Therefore, including additional El Niño SST variables, especially those with inconsistent variability, was redundant and did not improve the models' forecasting capabilities. However, different locations of SSTs can have different time responses that influence Taiwan's climate. Therefore, using multiple SST variables with different lags as inputs may improve the model performance when using the multiple SST indices. Nevertheless, the results of this study demonstrate that using one El Niño SST to forecast drought in Southern Taiwan is sufficient, and that complex models with additional El Niño SSTs are unnecessary. In addition, the ensemble model performance ranks middle in this work. Although the ensemble model is not superior, it is generally a useful scheme that is worth applying. 


\section{CONCLUSIONS}

This study proposed a probabilistic drought forecasting model to forecast drought in Southern Taiwan using the ENSO index. The proposed methodology used a concept similar to a Markov chain to construct the transition probability matrix used in the probabilistic drought forecasting model. Two types of forecasting architectures were constructed to forecast the drought one month ahead. Model 1 used the transition probability matrix of SPI and El Niño SSTs in the same month, and then applied autoregression models that provided one-month-ahead SSTs forecasts. Model 2 used the transition probability matrix pertaining to SPI in the present month and SSTs in the previous month. Both Models 1 and 2 presented satisfactory probabilistic forecasting results for forecasted drought probability distributions. Scoring based on the probability concept was proposed to quantitatively assess the probabilistic forecasting performance. The analytical results from these scores showed that Model 1 outperformed Model 2, indicating that El Niño SST in the same month is more informative for drought conditions in Southern Taiwan than is El Niño SST in the previous month. Comparing models with differing combinations of El Niño SST inputs revealed that models with a single El Niño SST input had good performances, but models with multiple El Niño SST inputs did not have high scores. This is because some El Niño regions (e.g., El Niño $1+2$ and El Niño 4) were more distant from each other, causing the SSTs of these regions to have low correlations. Therefore, using one El Niño SST to forecast drought in Southern Taiwan is sufficient, and complex models with additional El Niño SSTs are not recommended.

The division of SPI and SST states is optional, and the analytical results can be influenced by choice of interval. Following preliminary analysis, we used an SST interval increment of $0.2^{\circ} \mathrm{C}$ and an SPI interval increment of 1.0 to construct the state transition matrix. In addition, only the variable of drought in Southern Taiwan was studied, and one-monthahead drought was predicted. Additional cases (with different input variables, interval definition, local regions, large-scale ocean-atmospheric indices, lagged SST inputs, longer lead times, and so on) can be investigated in future studies.

Acknowledgments This research was supported by the National Science Council of Taiwan under grants NSC 992221-E-035-107 and NSC 100-2221-E-035-104.

\section{REFERENCES}

Bonaccorso, B., I. Bordi, A. Cancelliere, G. Rossi, and A. Sutera, 2003: Spatial variability of drought: An analysis of the SPI in Sicily. Water Resour. Manag., 17, 273-296, doi: 10.1023/A:1024716530289. [Link]

Chen, J. M. and M. M. Lu, 2000: Interannual variation of the Asian-Pacific atmospheric system in association with the northern summer SST changes. Terr. Atmos. Ocean. Sci., 11, 833-860.

Chen, J. M., T. Li, and C. F. Shih, 2008: Asymmetry of the El Niño-spring rainfall relationship in Taiwan. J. Meteorol. Soc. Jpn., 86, 297-312, doi: 10.2151/jmsj.86.297. [Link]

Chen, J. M., C. M. Hsieh, and J. S. Liu, 2012: Possible influences of ENSO on winter shipping in the North Pacific. Terr. Atmos. Ocean. Sci., 23, 397-411, doi: 10.3319/ TAO.2012.03.02.01(A). [Link]

Chen, S. T., C. C. Kuo, and P. S. Yu, 2009: Historical trends and variability of meteorological droughts in Taiwan. Hydrolog. Sci. J., 54, 430-441, doi: 10.1623/ hysj.54.3.430. [Link]

Deng, X., C. Hwang, R. Coleman, and W. E. Featherstone, 2008: Seasonal and interannual variations of the Leeuwin Current off Western Australia from TOPEX/Poseidon satellite altimetry. Terr. Atmos. Ocean. Sci., 19, 135-149, doi: 10.3319/TAO.2008.19.1-2.135(SA). [Link]

Dimitrakopoulos, A. P., M. Vlahou, C. G. Anagnostopoulou, and I. D. Mitsopoulos, 2011: Impact of drought on wildland fires in Greece: Implications of climatic change? Clim. Change, 109, 331-347, doi: 10.1007/ s10584-011-0026-8. [Link]

Edwards, D. C. and T. B. McKee, 1997: Characteristics of 20th century drought in the United States at multiple time scales. Climatology Report no.97-2, Department of Atmospheric Science, Colorado State University, USA.

Hallack-Alegria, M., J. Ramirez-Hernandez, and D. W. Watkins Jr., 2012: ENSO-conditioned rainfall drought frequency analysis in northwest Baja California, Mexico. Int. J. Climatol., 32, 831-842, doi: 10.1002/ joc.2310. [Link]

Hayes, M. J., M. D. Svoboda, D. A. Wilhite, and O. V. Vanyarkho, 1999: Monitoring the 1996 drought using the standardized precipitation index. Bull. Amer. Meteor. Soc., 80, 429-438, doi: 10.1175/1520-0477(1999)080< 0429:MTDUTS>2.0.CO;2. [Link]

Hendon, H. H., E. Lim, G. Wang, O. Alves, and D. Hudson, 2009: Prospects for predicting two flavors of El Niño. Geophys. Res. Lett., 36, L19713, doi: 10.1029/2009GL040100. [Link]

Huang, W. C. and L. C. Yuan, 2004: A drought early warning system on real-time multireservoir operations. Water Resour. Res., 40, W06401, doi: 10.1029/ 2003WR002910. [Link]

Huang, W. C. and C. C. Chou, 2008: Risk-based drought early warning system in reservoir operation. $A d v$. Water Resour., 31, 649-660, doi: 10.1016/j.advwatres.2007.12.004. [Link]

Janicot, S., V. Moron, and B. Fontaine, 1996: Sahel droughts and ENSO dynamics. Geophys. Res. Lett., 23, 515-518, doi: 10.1029/96GL00246. [Link] 
Ji, L. and A. J. Peters, 2003: Assessing vegetation response to drought in the northern Great Plains using vegetation and drought indices. Remote Sens. Environ., 87, 85-98, doi: 10.1016/S0034-4257(03)00174-3. [Link]

Jiang, Z., G. T. J. Chen, and M. C. Wu, 2003: Large-scale circulation patterns associated with heavy spring rainevents over Taiwan in strong ENSO and non-ENSO years. Mon. Weather Rev., 131, 1769-1782, doi: 10.1175// 2561.1. [Link]

Kao, H. Y. and J. Y. Yu, 2009: Contrasting eastern-Pacific and central-Pacific types of ENSO. J. Climate, 22, 615-632, doi: 10.1175/2008JCLI2309.1. [Link]

Kuo, C. C., T. Y. Gan, and P. S. Yu, 2010: Wavelet analysis on the variability, teleconnectivity, and predictability of the seasonal rainfall of Taiwan. Mon. Weather Rev., 138, 162-175, doi: 10.1175/2009MWR2718.1. [Link]

Kuo, C. H., T. C. Yang, C. M. Kuo, S. T. Chen, and P. S. $\mathrm{Yu}, 2012$ : Development of drought probability forecasting models based on ENSO indices - A case study in Southern Taiwan. J. Taiwan Agric. Eng., 58, 13-32. (in Chinese)

Lana, X., C. Serra, and A. Burgueño, 2001: Patterns of monthly rainfall shortage and excess in terms of the standardized precipitation index for Catalonia (NE Spain). Int. J. Climatol., 21, 1669-1691, doi: 10.1002/ joc.697. [Link]

Li, T. and B. Wang, 2005: A review on the western North Pacific monsoon: Synoptic-to-interannual variabilities. Terr. Atmos. Ocean. Sci., 16, 285-314.

Liu, X., Z. Xu, and R. Yu, 2012: Spatiotemporal variability of drought and the potential climatological driving factors in the Liao River basin. Hydrol. Process., 26, 1-14, doi: 10.1002/hyp.8104. [Link]

Lloyd-Hughes, B. and M. A. Saunders, 2002: A drought climatology for Europe. Int. J. Climatol., 22, 1571-1592, doi: 10.1002/joc.846. [Link]

Lu, M. M., 2002: The biennial oscillations in Taiwan. Terr. Atmos. Ocean. Sci., 13, 469-498.

Manatsa, D., W. Chingombe, H. Matsikwa, and C. H. Matarira, 2008: The superior influence of Darwin Sea level pressure anomalies over ENSO as a simple drought predictor for Southern Africa. Theor. Appl. Climatol., 92, 1-14, doi: 10.1007/s00704-007-0315-3. [Link]

McKee, T. B., N. J. Doesken, and J. Kleist, 1993: The relationship of drought frequency and duration to time scales. Eighth Conference on Applied Climatology, Department of Atmospheric Science Colorado State University, 179-184, Anaheim, California.

Mishra, A. K. and V. R. Desai, 2005: Drought forecasting using stochastic models. Stochast. Environ. Res. Risk Assess., 19, 326-339, doi: 10.1007/s00477-005-0238-4. [Link]

Pasho, E., J. J. Camarero, M. de Luis, and S. M. Vicente-Serrano, 2011: Impacts of drought at different time scales on forest growth across a wide climatic gradient in north-eastern Spain. Agric. For. Meteorol., 151, 18001811, doi: 10.1016/j.agrformet.2011.07.018. [Link]

Piccarreta, M., D. Capolongo, and F. Boenzi, 2004: Trend analysis of precipitation and drought in Basilicata from 1923 to 2000 within a southern Italy context. Int. J. Climatol., 24, 907-922, doi: 10.1002/joc.1038. [Link]

Quiring, S. M. and T. N. Papakryiakou, 2003: An evaluation of agricultural drought indices for the Canadian prairies. Agric. For. Meteorol., 118, 49-62, doi: 10.1016/ S0168-1923(03)00072-8. [Link]

Rajagopalan, B., E. Cook, U. Lall, and B. K. Ray, 2000: Spatiotemporal variability of ENSO and SST teleconnections to summer drought over the United States during the twentieth century. J. Climate, 13, 4244-4255, doi: $10.1175 / 1520-0442(2000) 013<4244:$ SVOEAS $>2$ .0.CO;2. [Link]

Ryu, J. H., M. D. Svoboda, J. D. Lenters, T. Tadesse, and C. L. Knutson, 2010: Potential extents for ENSO-driven hydrologic drought forecasts in the United States. Clim. Change, 101, 575-597, doi: 10.1007/s10584009-9705-0. [Link]

Shiau, J. T., 2006: Fitting drought duration and severity with two-dimensional copulas. Water Resour. Manag., 20, 795-815, doi: 10.1007/s11269-005-9008-9. [Link]

Smith, T. M. and R. W. Reynolds, 2003: Extended reconstruction of global sea surface temperatures based on COADS data (1854-1997). J. Climate, 16, 1495-1510, doi: 10.1175/1520-0442-16.10.1495. [Link]

Smith, T. M. and R. W. Reynolds, 2004: Improved extended reconstruction of SST (1854-1997). J. Climate, 17, 2466-2477, doi: 10.1175/1520-0442(2004)017<2466:I EROS $>2.0 . C O ; 2 . ~[\underline{\text { Link}}]$

Smith, T. M., R. W. Reynolds, T. C. Peterson, and J. Lawrimore, 2008: Improvements to NOAA's historical merged land-ocean surface temperature analysis (1880-2006). J. Climate, 21, 2283-2296, doi: 10.1175/2007JCLI2100.1. [Link]

Tsakiris, G. and H. Vangelis, 2004: Towards a drought watch system based on spatial SPI. Water Resour. Manag., 18, 1-12, doi: 10.1023/B:WARM.0000015410.47014. a4. [Link]

Vicente-Serrano, S. M., J. I. López-Moreno, L. Gimeno, R. Nieto,E.Morán-Tejeda,J.Lorenzo-Lacruz,S.Beguería, and C. Azorin-Molina, 2011: A multiscalar global evaluation of the impact of ENSO on droughts. J. Geophys. Res., 116, D20109, doi: 10.1029/2011JD016039. [Link]

Wen, L., K. Rogers, J. Ling, and N. Saintilan, 2011: The impacts of river regulation and water diversion on the hydrological drought characteristics in the Lower Murrumbidgee River, Australia. J. Hydrol., 405, 382-391, doi: 10.1016/j.jhydrol.2011.05.037. [Link]

Wu, H., M. J. Hayes, A. Weiss, and Q. Hu, 2001: An 
evaluation of the standardized precipitation index, the China-Z Index and the statistical Z-Score. Int. J. Climatol., 21, 745-758, doi: 10.1002/joc.658. [Link]

Yu, J. Y. and S. T. Kim, 2010: Identification of centralPacific and eastern-Pacific types of ENSO in CMIP3 models. Geophys. Res. Lett., 37, L15705, doi: 10.1029/2010GL044082. [Link]

Yu, J. Y., Y.Zou, S. T. Kim, and T. Lee, 2012: The changing impact of El Niño on US winter temperatures. Geophys. Res. Lett., 39, L15702, doi: 10.1029/2012GL052483. [Link]

Zhang, Y. and T. Li, 2008: Influence of the sea surface temperature in the Indian Ocean on the in-phase transition between the South Asian and North Australian summer monsoons. Terr. Atmos. Ocean. Sci., 19, 321-329, doi: 10.3319/TAO.2008.19.3.321(A). [Link] 